\title{
Left Atrial Appendage (LAA) Closure-Device Disengagement as a Serious Complication and How it Can Be Easily Removed
}

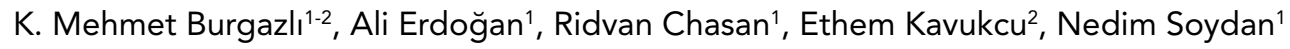 \\ ${ }^{1}$ Department of Cardiology and Angiology, JL-University of Giessen, Giessen, Germany \\ ${ }^{2}$ Department of Internal Medicine, Angiologie, Medical and Research Center Wuppertal, Wuppertal, Germany
}

\begin{abstract}
A stroke attack in the brainstem area as a serious complication of atrial fibrillation (AF) in a 51 year old woman with known paroxysmal AF (CHADS 2 score 3) was treated with LAA occlusion procedure after the complication of arterial bleeding secondary to anticoagulation therapy. LAA closure device embolisation was developed following the LAA occlusion procedure. The device was located and removed successfully from the systemic circulation.
\end{abstract}

Key Words: Atrial fibrillation, LAA occlusion, device embolisation

Received: 10.04.2012 Accepted: 28.05.2012

\section{Introduction}

Atrial fibrillation (AF) is the most common sustained arrhythmia causing substantial morbidity and mortality. Stroke is the most serious complication of AF. The commonly used system to predict the stroke risk in AF is the CHADS2 score.

Anticoagulation therapy is the method of choice for prevention of thromboembolic events in AF. Bleeding (cerebral, gastrointestinal, etc.) leads to interruption of treatment in $6.5 \%$ of patients per year. Recent data clarify the acceptable risk-to-benefit ratio for the Left Atrial Appendage (LAA) closure as an alternative to chronic warfarin therapy (1-4).

\section{Case Report}

A 51 year old woman with known paroxysmal AF (CHADS² score 3) had a stroke attack in the brainstem area. Anticoagulant therapy was started and an arterial bleeding in the ethmoidal area was reported. So, we stopped the anticoagulant therapy and decided to apply an LAA occlusion procedure.

The procedure was performed with local anesthesia and mild sedation. After the transseptal punction, we measured the diameter of the LAA by contrasted X-Ray and transesophageal echocardiography (TEE) as $18 \mathrm{~mm}$ (Figure 1). We placed a $21 \mathrm{~mm}$ occluder (AMPLATZER ${ }^{\circledR}$ Cardiac Plug, AGA Medical Corporation, North Plymouth, MN 55442, USA) to the LAA (Figure 2). Then the drag test was performed. During the procedure we observed many polymorphic ventricular premature beats which did not fit with the actual status of the patient. We diagnosed that the LAA occluder was disengaged from its site and was found in the left ventricle (LV) (Figure 3). Through the arterial access (10 French long sheath), by means of a pig- tail catheter, we stabilized the occluder in the LV. Then we manipulated the device with a snare catheter (Multi-Snare ${ }^{\circledR}$, PFM Medical, Carlsbad, California, 92008, USA) in the LV. It escaped and gained access into the systemic circulation. Through X-Ray we located it in the abdominal aorta (Figure 4), and removed it with the snare catheter.

\section{Discussion}

Anticoagulant therapy leads to bleeding complications in some patients. Although LAA occlusion is a good alternative therapy method for patients who cannot tolerate anticoagulation in $A F$, it has its own complication risks. LAA occlusion device disengagement is a serious risk, especially in the first few days after intervention, because it may lead to valve occlusion (mitral and aortic valve) and occlusion of systemic circulation arteries (A. carotis, A. subclavia, etc.). An obliteration of the AV can be life threatening for the patient and lead to an emergency resuscitation. This patient had sinus rhythm during the procedure, which may ease device embolisation. LAA closure and device adherence seems superior during AF. In the case of device disengagement we suggest primarily a pigtail catheter placed retrograde into the LV in order to keep the AV open and stabilize the device in LV. Then, the occluder could be removed with a Multi Snare ${ }^{\circledR}$ catheter more safely. However, it may not be able to stabilize the device because of the high turbulence in LV. If this does not succeed, it is easier to catch and remove the device in the systemic circulation.

\section{The pigtail catheter usage has two advantages:}

1. stabilisation in LV, and

2. in case of failure in stabilisation, avoiding AV occlusion 


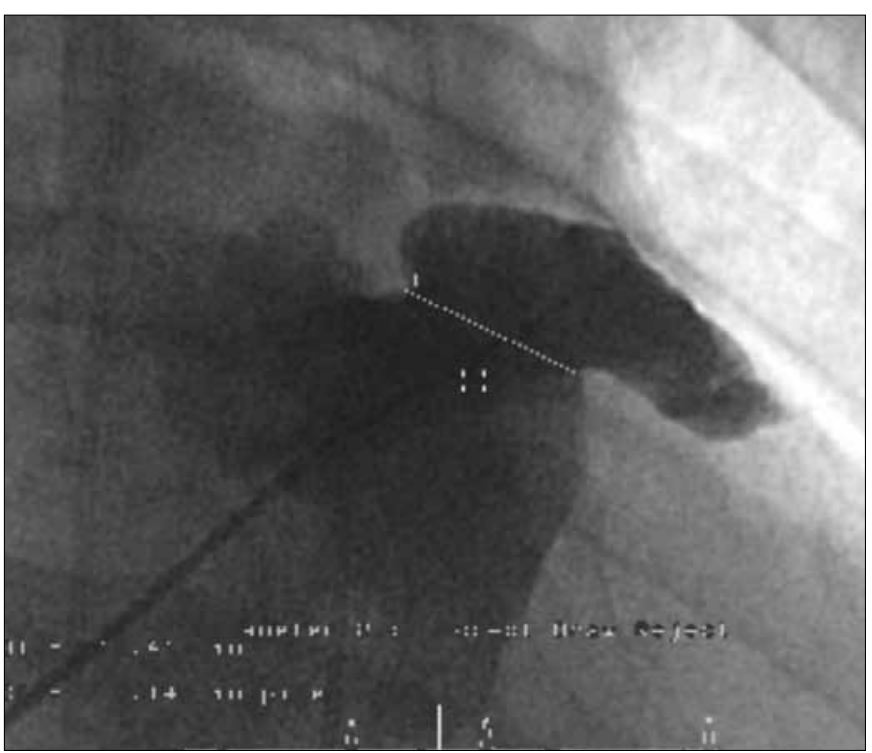

Figure 1. Measurement of LAA diameter

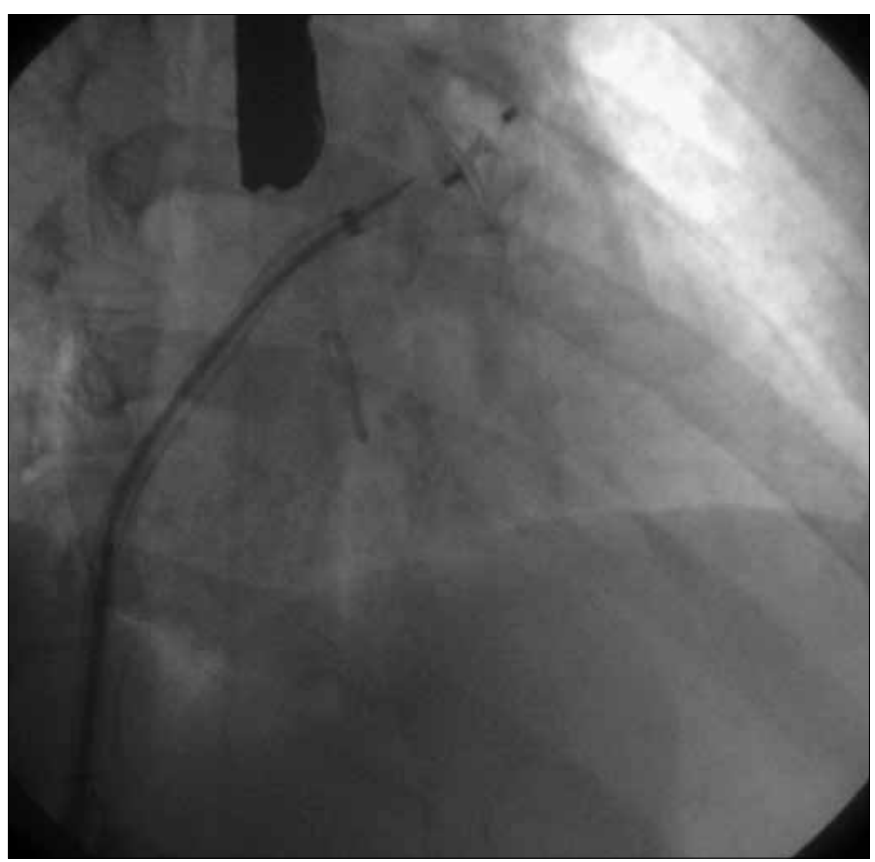

Figure 2. Placement of the device in LAA

\section{Conclusion}

This is the first report of LAA closure device embolisation and detailed explanation of the removal. In a multi-center and a single center study, in total five device embolisations are reported in three and two patients respectively $(3,4)$. Worldwide, 700 cases have been performed with the AMPLATZER device, and 6 cases of device embolisation are verbally confirmed from the AGA Medical Corporation. No further details

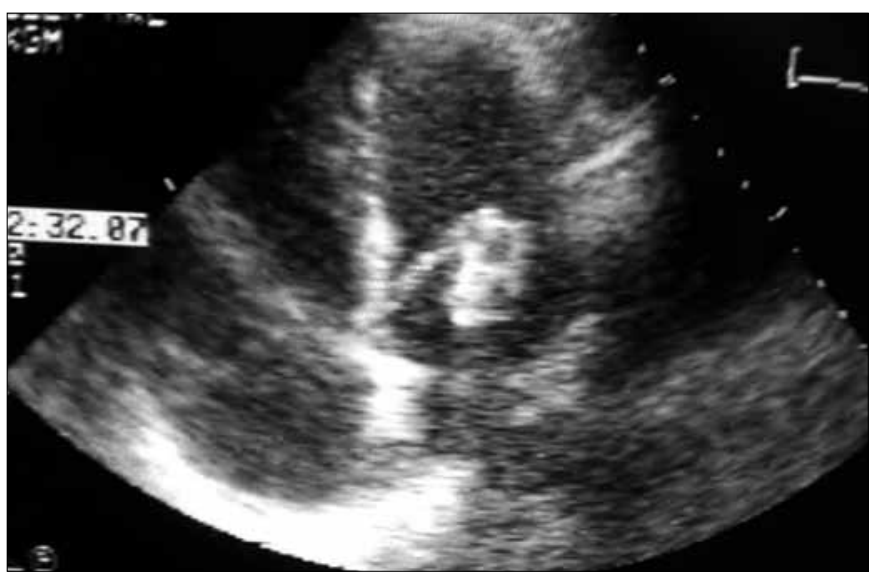

Figure 3. Localization of device in LV (transthoracic echocardiography)

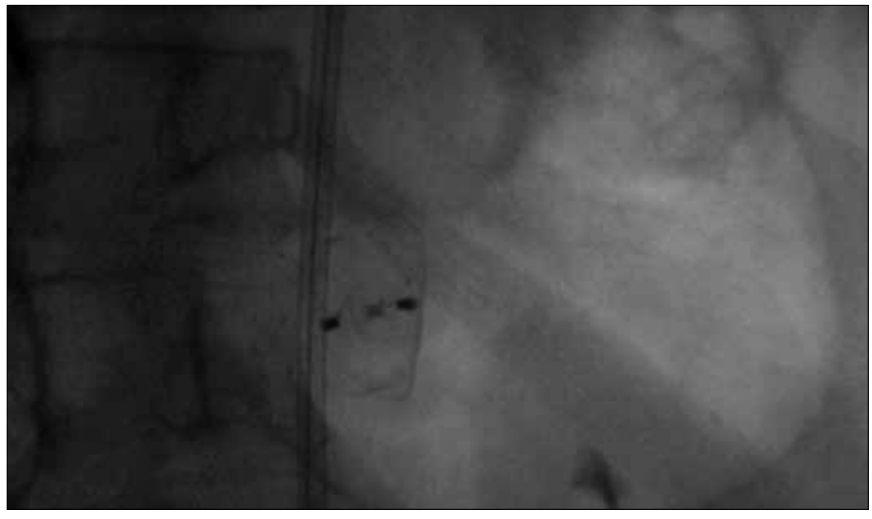

Figure 4. Localization of the device in aorta abdominalis

are available regarding the actions to be taken under such conditions.

\section{Conflict of Interest}

No conflict of interest was declared by the authors.

\section{References}

1. Ostermayer SH, Reisman M, Kramer PH, Matthews RV, Gray WA, Block PC, et al. Percutaneous left atrial appendage transcatheter occlusion [PLAATO system] to prevent stroke in high risk patients with non rheumatic atrial fibrillation: results from the international multicenter feasibility trials. J Am Coll Cardiol 2005;46:9-14. [CrossRef]

2. Sick PB, Schuler G, Hauptmann KE, Grube E, Yakubov S, Turi ZG, et al. Initial worldwide experience with the WATCHMAN left atrial appendage system for stroke prevention in atrial fibrillation. $J$ Am Coll Cardiol 2007;49:1490-5. [CrossRef]

3. Holmes DR, Reddy VY, Turi ZG. Percutaneous closure of the left atrial appendage versus warfarin therapy for prevention of stroke in patients with atrial fibrillation: a randomized noninferiority trial. Lancet 2009;374:534-42. [CrossRef]

4. Park JW, Bethencourt A, Sievert H. Left atrial appendage closure with amplatzer cardiac plug in atrial fibrillation - Initial European experience. Catheter Cardiovasc Interv 2011;77:700-6. [CrossRef] 